\title{
A systematic analysis of the friction losses on bearings of modern turbocharger
}

\begin{abstract}
In the article, a novel test rig for determining the friction losses of modern turbocharger is presented. The friction torque of the bearing of turbocharger can be measured direct and stationary at any speed up to 100,000 min-1 by the friction test rig developed by the Ostfalia, University of Applied Science (UAS). Since 2010, over 50 turbochargers were measured on the test bench in extensive measurement series. The results give valuable and new insights of the influence of the next parameters on the bearing friction losses: oil temperature, oil pressure, thrust force and oil flow rate. Furthermore, a comparison between the different bearing types (semi-floating, full floating and ball bearings) was performed. The main observations and results are discussed in the scientific article.
\end{abstract}

Key words: friction power, test rig, turbocharger, floating bearing, ball bearing, oil temperature, oil pressure, thrust force

\section{Introduction}

One of the possibilities to improve the efficiency new combustion engines is to optimize the turbocharging systems. A turbocharger with high efficiency and excellent dynamic properties is essential for low fuel consumption combined with good driving performance. The overall efficiency is in this case composed of the response levels of the turbine, the compressor and the mechanical efficiency of bearing system. A CFD simulation can be used for a forecast of the turbine and compressor efficiencies. On a powerful hot gas test rig the simulated results can be confirmed [1].

Within the framework of research projects the simulation models have been established in order to calculate the lubricating properties of journal and thrust bearings. The direct measurement of friction losses of a bearing system under real conditions is up to date difficult to measure $[2,3]$.

Therefore, the research group for thermodynamics and alternative driving systems of the Ostfalia, UAS in Wolfsburg works, since 2010 on a friction test rig to determine with different measuring method the friction losses of turbocharger bearings.

\section{Measurements of friction losses on bearings of turbochargers}

The shaft of modern turbocharger rotates up to 300,000 $\mathrm{rpm}$. In order to achieve these high speeds and realize a long life the mechanical demands on these bearings are a big challenge. On the shaft of modern turbochargers an axial thrust- and radial bearing are applied.

In order to quantify the most important properties of a bearing, a test rig was set up which can detect the friction power or the friction torque of a turbocharger shaft. Other important factors like the oil temperature and oil pressure can be varied by the test rig. Figure 1 shows the basic structure of the test rig.

The determination of the frictional power can be record direct or indirect. With the direct measurement method, the torque, which is caused by the friction in the bearing, is detected by a torque sensor. The shaft is driven by a high speed electric engine, which is controlled by a pulse width modulation. The engine is mounted on a micro positioning unit within the test bench adjustable in three directions.

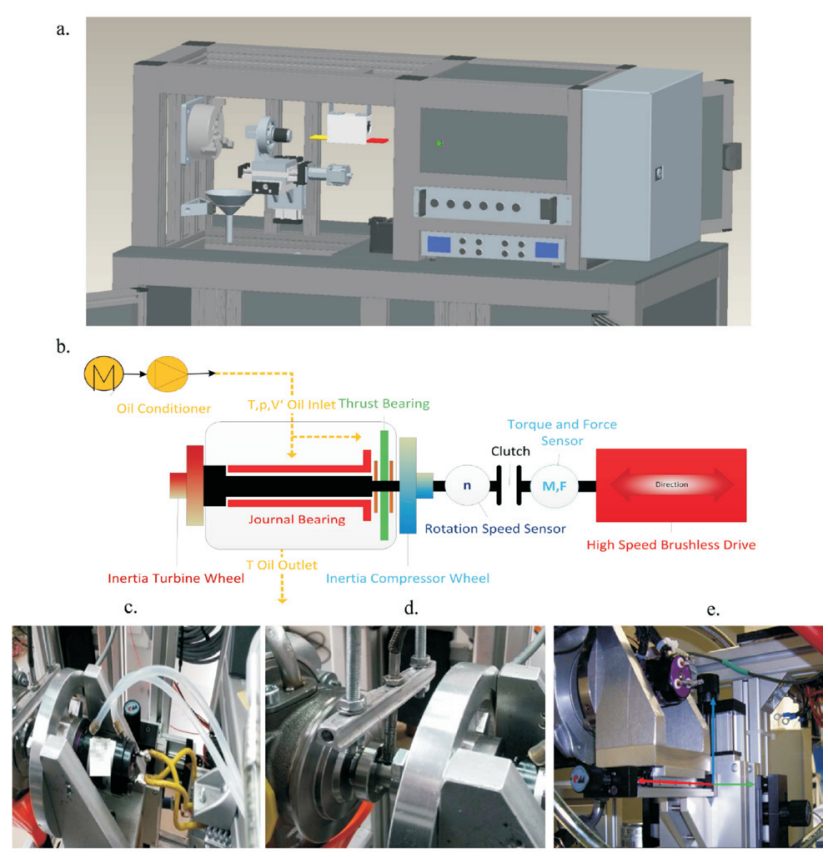

Fig. 1. The Ostfalia friction power test rig: a) CAD representation of test rig, b) schematic structure of test rig with measurements technique, c) drive engine with torque sensor, d) clutch with speed sensor e) drive engine with linear adjustment

The turbocharger can be mounted on the turbine or the compressor side of the bearing housing on the test bench. The construction of the test rig ensures an orthogonal alignment with negligible angular displacement $\left(<0.1^{\circ}\right)$ between turbocharger and the shaft of electric engine. The connection between the shaft of the engine and the turbine shaft is made by a torx-clutch. This type of clutch allows certain angle resilience when the shaft during operation due to the lubrication film begins to "swim". With the micrometer positioning unit it is possible to set up the alignment exactly. 
The torque of the shaft is measured by detecting the reaction force of the electric drive by means of a full Wheatstone bridge with strain gauges. The sensor is screwed to the electric drive and has in contrast to a torque - measuring shaft no speed limitation. The speed measurement is done by an inductive speed sensor.

To investigate the thrust force on the turbocharger (TC) bearings systems, the thrust bearing of the turbocharger is loaded by a force acting in the axial direction, so the thrust force can be measured with a special axial force sensor with strain gauges. The thrust force is set up by variation the direction of the linear actuator, which is mounted at the linear unit in the axial direction. By driving the electric drive against the turbocharger shaft, the clutch is closed and the thrust force can be applied. The torx-clutch can only push the TC shaft in direction of thrust bearing, but by changing the drive side for example on turbine side, it's possible to vary the thrust force. So it's possible to determine friction losses by positive or negative thrust force.

The lubricant supply of the bearing and the shaft is ensured by an oil conditioning unit. This consists of an oil pump, an oil pressure sensor and an oil heating and oil cooling system so the temperature can be vary between $0{ }^{\circ} \mathrm{C}-120{ }^{\circ} \mathrm{C}$ and the pressure between 2-6 bar absolute. A flow sensor measured the oil volumetric flow.

The control and regulation and the visualization of all measured variables is carried out by the software "LabView". The software can set and read out the measurement data and control parameters via PXI system from National Instruments. Measurements can be performed with or without inertia masses for compressor and turbine wheels.

First, a measurement point is adjusted at a desired speed. After a short time, which is used for stabilization of the parameters like oil pressure, oil temperature, thrust force and speed, a measurement with a frequency of 25-100 Hz over a period of $10 \mathrm{~s}$ is recorded. This measurement results in a high number of measurement values, an arithmetic average is built for each parameter.

With the indirect method of the frictional power measurements inertia mass of turbine a compressor wheel is mounting on the shaft. The shaft is accelerated to a speed of 100,000 $\mathrm{rpm}$, after a delay time, the electric drive stops and is disengaged, so the clutch is opened. This is realized by a rapid return of the linear actuator in the axial direction. The speed drop of the outgoing shaft is detected at high frequency. The drop of the speed and the known inertia mass the friction torque can be calculated.

\section{Test results}

This section describes the results and presented the different analyzed parameter.

\subsection{Variation of the oil temperature}

By determining the influence of the oil temperature on the friction of turbocharger shaft without applying an axial load to a speed range of 5,000 till 80,000 rpm was measured at a speed of 5,000 rpm increment. The oil supply temperature has been conditioned to $0^{\circ} \mathrm{C}, 50^{\circ} \mathrm{C}, 90^{\circ} \mathrm{C}$ and $110^{\circ} \mathrm{C}$ with a constant pressure of 3 bar (absolute).

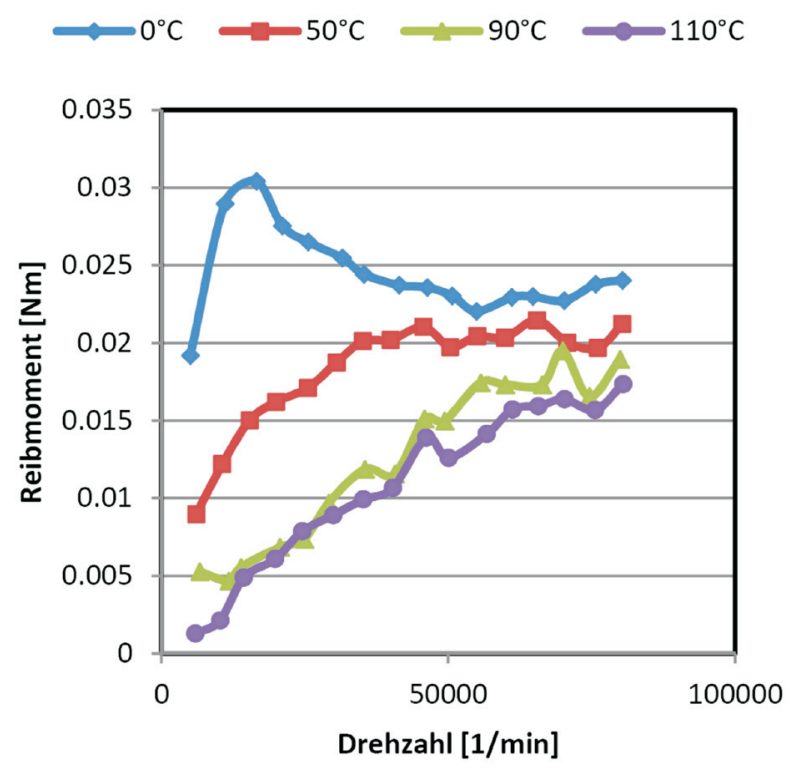

Fig. 2. The friction torque under the influence of oil temperature

Figure 2 shows the trend of the friction torque by different oil temperatures over the speed. The friction torque at $90{ }^{\circ} \mathrm{C}$ and $110^{\circ} \mathrm{C}$ oil temperature has a progressive trend. Both friction types the adhesive and the mixed friction are already overcome in the initial rotational speed of $5000 \mathrm{rpm}$. An increase in the oil temperature results in a reduction of the friction torque of the plain bearing. The increase in the friction torque at low speed and oil temperature $0{ }^{\circ} \mathrm{C}$ and $50{ }^{\circ} \mathrm{C}$ can be observed.

An increased oil temperature leads to a decrease of the viscosity. This viscosity drop is explained by the cohesive forces of the molecules. It is caused by the lower shear stress $\tau$ during the rotation of the shaft.

Lower shear stress requires a lower force to apply the movement of the shaft relative to the bearing tin. So the friction torques in Fig. 2 decrease dependent the increase of oil temperature.

At higher speeds there is a higher friction loss inside the bearing. This increased friction power causes an increasing local temperature, which result in a decrease of the oil viscosity so the real oil temperature is much higher than the inlet temperature.

At higher speeds, due to the lower viscosity, lower shear forces occur and the friction decreases. At lower shaft speeds, the frictional power (the heat generation due to friction) within the bearing is too small to induce a high local fluid temperature. The high torque at $0{ }^{\circ} \mathrm{C}$ and $50{ }^{\circ} \mathrm{C}$ in lower speeds are justified by the fact that the real lubricating film temperature within the bearing approaches in this field of oil supply temperature and leads to a high viscosity. There is a higher friction loss inside the bearing, between the shaft and tin. This increased friction power obtained a local temperature increase, which leads to a decreased viscosity.

The Figure 3 shows the trend of the oil flow by variation of the oil temperature at constant oil pressure for different 
speed. The oil flow increases with higher oil temperatures. The oil flow by $0{ }^{\circ} \mathrm{C}$ and $50^{\circ} \mathrm{C}$ increased with a linear trend depend by the speed, while the oil volumetric flow decrease linearly at $90{ }^{\circ} \mathrm{C}$ and $110{ }^{\circ} \mathrm{C}$ with the speed. This is, as already explained, due to a throttle effect in dependence by the centrifugal force in the full-floating bearing.

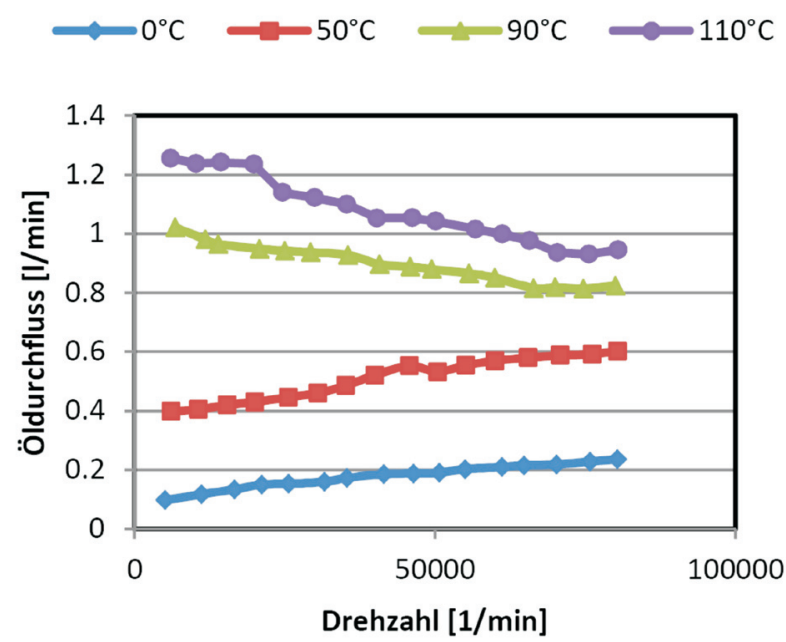

Fig. 3. The oil volumetric flow as a function of oil temperature

Figure 4 shows the trend of the friction losses for different oil temperatures in dependence of the speed. The friction loss increases with each setting of oil temperature proportionally with the speed.

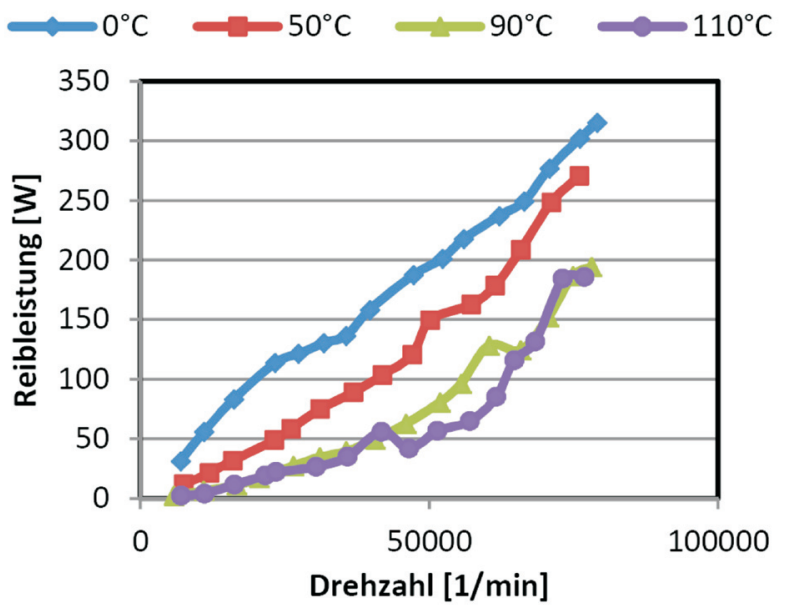

Fig. 4. Friction power as a function of oil temperature

\subsection{Direct- and indirect measurement of friction power loss}

The presented test rig in chapter 2 enables a direct or an indirect measurement of the friction loss in bearing systems of turbochargers. In the direct method every speed points is adjusted stationary and the torque on the electric drive is captured. With the indirect measurement method, which is popular in use, the TC shaft is accelerated to $100,000 \mathrm{rpm}$ after a persist time the drive stops and a linear actuator disengages the clutch. The drop of speed changing by a known time can be measured, so the friction loss power can be calculated. To achieve the longest possible run of the shaft, it is important to mount an inertia mass fitted to the turbine and compressor wheels. The direct determination of friction power is carried out for reasons of comparability with inertia masses. Both measurement methods are carried out by an oil pressure of 3 bar and without thrust force. Figure 5 shows the friction torque at $90{ }^{\circ} \mathrm{C}$ and $30{ }^{\circ} \mathrm{C}$ oil temperature.
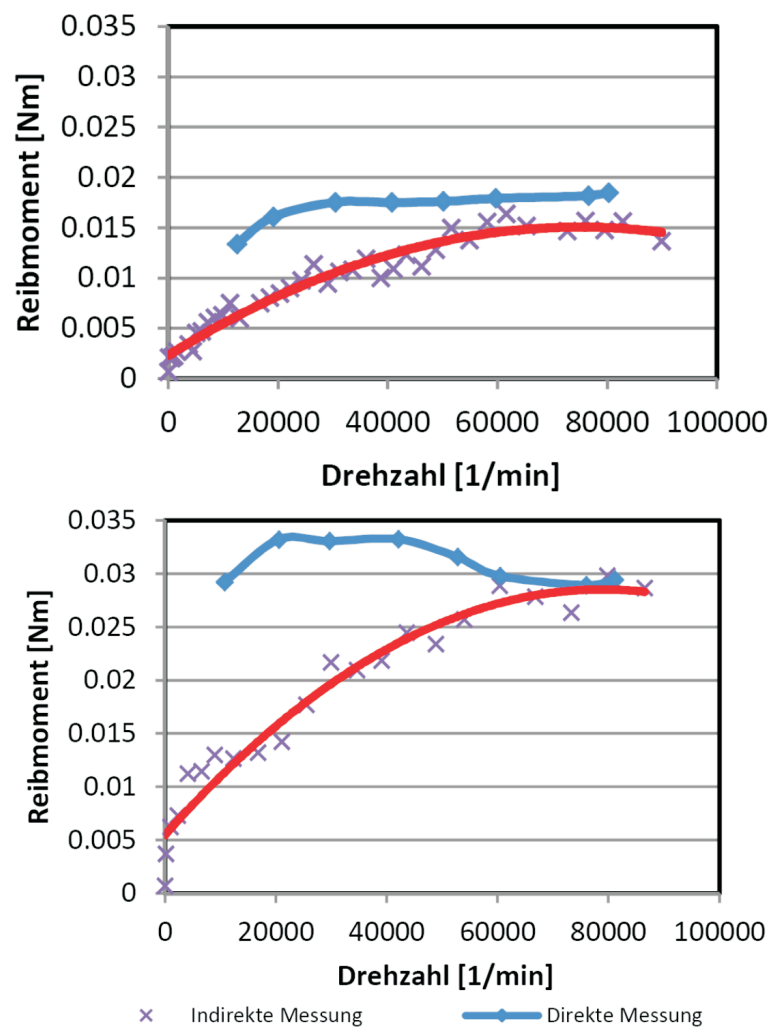

Fig. 5. The results of the direct- and indirect friction torque measurement with 3 bar oil pressure (top $90{ }^{\circ} \mathrm{C}$ inlet temperature and bottom $30^{\circ} \mathrm{C}$ inlet temperature)

The results of the two measurement methods show that there are differences in both trends of the friction torque in all speed ranges. At $30{ }^{\circ} \mathrm{C}$ inlet oil temperature there are big differences between the two methods of measurement at speeds below $60,000 \mathrm{rpm}$ and greater than $90{ }^{\circ} \mathrm{C}$ inlet oil temperature. At speeds above 60,000 rpm, the curves approach each other. At $90{ }^{\circ} \mathrm{C}$ inlet oil temperature, the difference between the friction torque with increasing speed decreases. For a more accurate interpretation of the measurement results, the oil supply and the oil outlet temperatures are depend on the shaft rotation - shown in Fig. 6.

It can be seen that the changes of oil temperature at $30{ }^{\circ} \mathrm{C}$ oil inlet temperature by the indirect measurement method is much higher than the direct method. There is a big temperature differences between inlet and outlet temperature at the two measurement methods. While the difference in temperature with increasing speed is gradually decreased greater in the stationary measurements (maximum of about $14^{\circ} \mathrm{C}$ ), the temperature difference increases linearly with the indirect measurement method (up to about $24^{\circ} \mathrm{C}$ ). The 
main difference in the friction torque in the indirect dynamic roll-out measurement method is created by holding time of $30 \mathrm{~s}$. Here the produced friction losses dissipated in the local lubricant and the components of the bearing system, so that the real local temperature is much higher than the supplied oil inlet temperature. So the viscosity of the oil which is in the bearing heats up, whereby the viscosity decreases exponentially with increasing temperature and decrease the shear stresses between the bearing tin and the shaft.
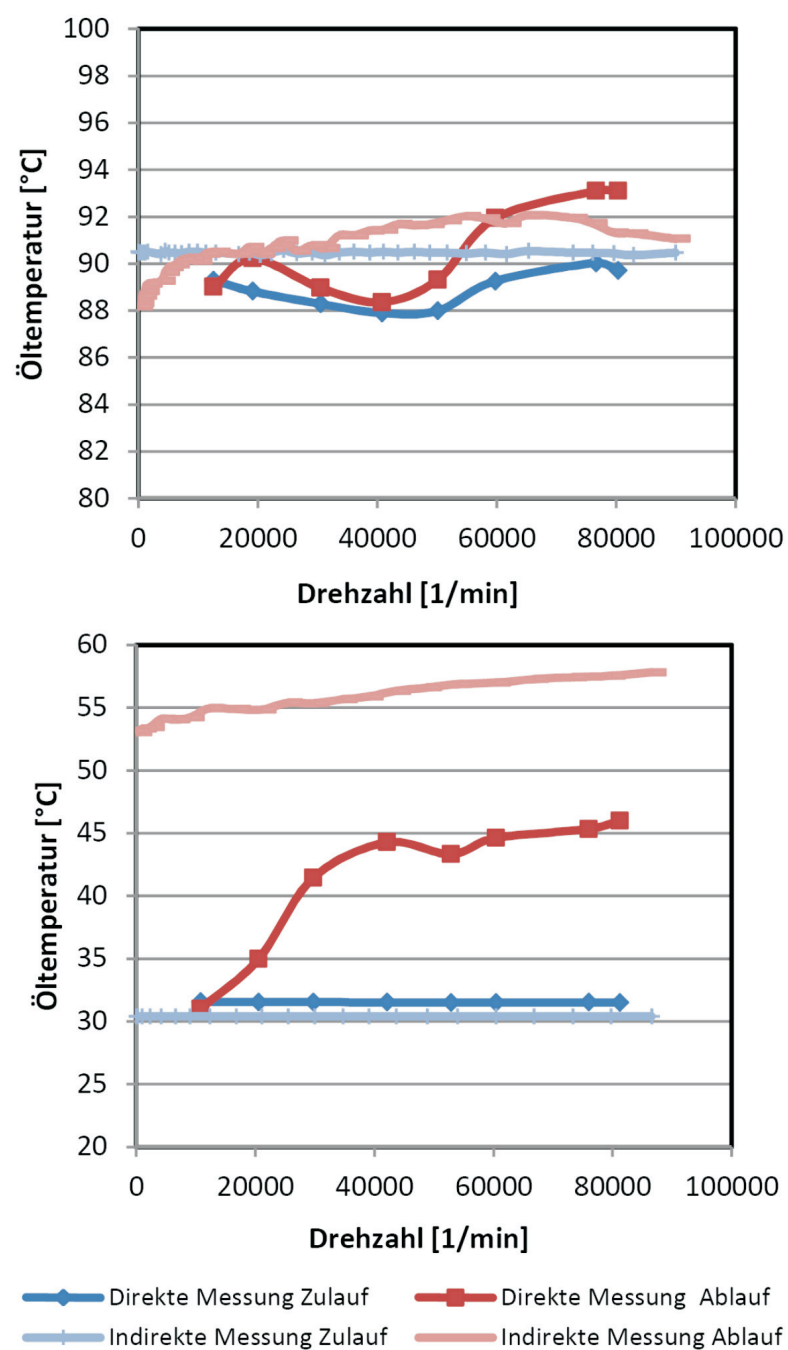

Fig. 6. The inlet and outlet oil temperatures by different measurement methods (top $90{ }^{\circ} \mathrm{C}$ inlet temperature and bottom $30^{\circ} \mathrm{C}$ inlet temperature)

By rolling-out the shaft, the bearing assembly is cooled slowly. So at low speeds, the real temperature of the lubrication in the turbocharger by the indirect measurement method is significantly higher than the direct method. This effect results in a significantly lower friction torque. At $30{ }^{\circ} \mathrm{C}$ and $90{ }^{\circ} \mathrm{C}$, the curves of friction torque between the two measurements variations are approaching at approx. 60,000 rpm. Above this speed, there is a good correlation between the two measurement methods. At lower speeds (below 60,000 $\mathrm{rpm}$ ) the difference between the two measurement methods is significantly higher.
The difference is due to the aforementioned hypothesis significantly more pronounced than an oil temperature of $30{ }^{\circ} \mathrm{C}$. At oil temperature of $110^{\circ} \mathrm{C}$ there is almost a full agreement of the two measurements.

Because the information content of the direct measurement method is higher, in this article all other measurements were carried out by this way.

\subsection{Variation of the oil pressure}

In this experiment, the turbocharger shaft is measured without thrust force in a speed range of $10,000 \mathrm{rpm}-80,000$ $\mathrm{rpm}$. The oil pressure is varied in a range from 2 bar -6 bar (absolute) by an oil temperature of $90^{\circ} \mathrm{C}$. To determine the frictional torque over the speed range are determined by the friction torque sensor.

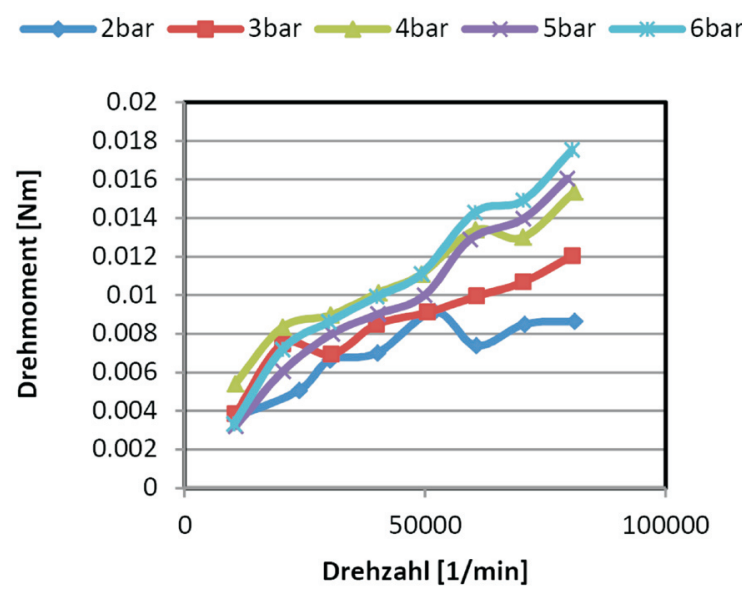

Fig. 7. The friction torque by variation the oil pressure at $90{ }^{\circ} \mathrm{C}$

Figure 7 shows the trend of the friction torque by variation of the oil pressures over the speed. The friction torque increases with the speed. In the speed range below 50,000 $\mathrm{rpm}$, the curves of the respective oil supply pressures do not show major differences. At speeds in excess of 50,000 rpm, the curves are drifting apart with increasing speed. It is striking that at $80,000 \mathrm{rpm}$ and 2 bar absolute oil pressure is the lowest and the highest friction arises at 6bar absolute oil pressure. One explanation for this is shown the behavior of the oil flow. Figure 8 illustrates the trend of the oil flow at various the oil pressures on the speed.

An increase in the oil pressure causes an increase in the oil volumetric flow. A higher oil flow does not necessarily lead to a greater volume flow through the plain bearing. The most of the oil flows around the journal bearing and cools the bearing tin. Due to the higher heat output of the plain bearing of the lubricating film is cooled and the local viscosity increases resulting in increased friction torque and friction power. This is particularly noticeable at high speeds, because there, caused by the proportional dependence to the speed, generally higher friction losses. Higher oil flow rates lead to higher splash losses in plain bearings. Their impact is a higher friction torque and a higher friction power. Depending on the design of the plain bearing, the pressure dependence of the friction power is more or less pronounced. 


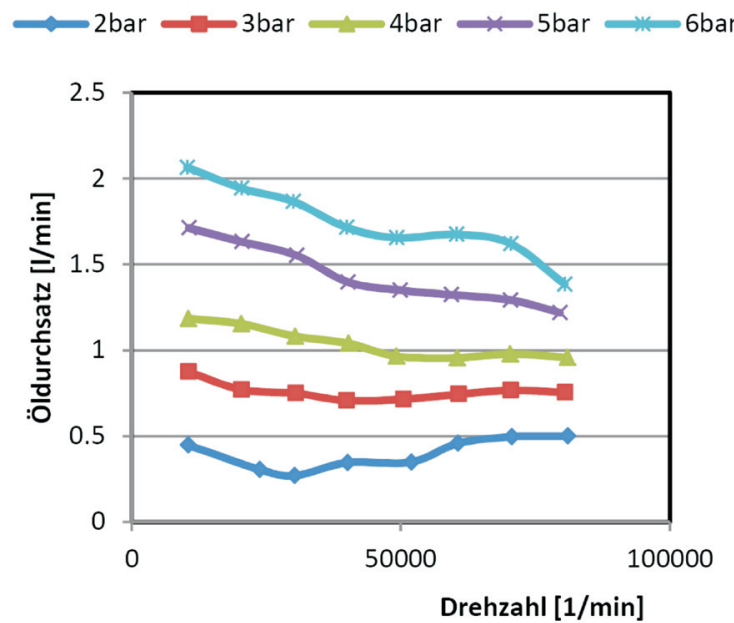

Fig. 8. The oil volumetric flow by variation the oil pressure at $90{ }^{\circ} \mathrm{C}$

\subsection{Variation of the shaft bearings}

In the following variation three different bearing systems options are compared in terms of frictional power, friction torque and volumetric oil flow. In order to clarify the possible influence of the mounting, factors such as the oil temperature and oil pressure are constant $\left(90^{\circ} \mathrm{C}, 3\right.$ bar $)$. The measurement is achieved without use a thrust force in a speed range from $5000 \mathrm{rpm}$ to $80,000 \mathrm{rpm}$.

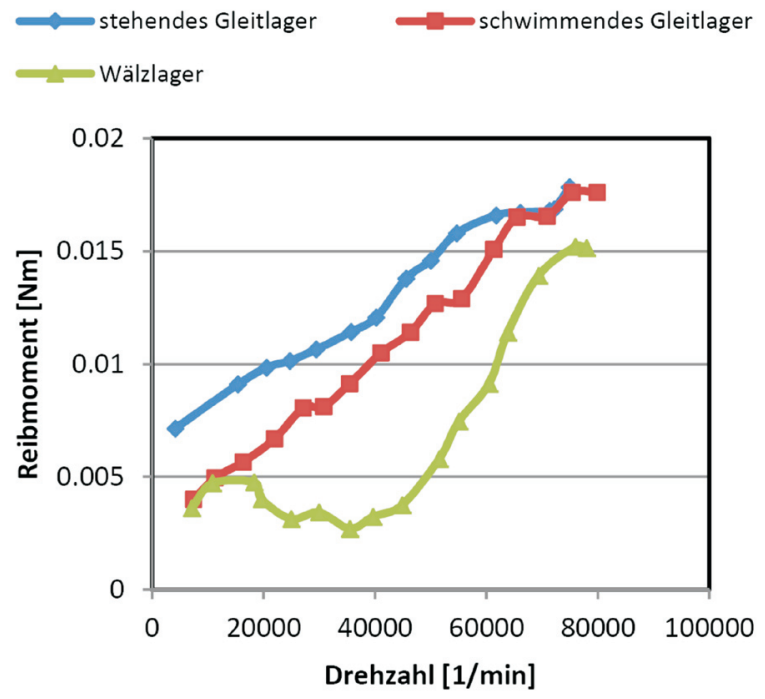

Fig. 9. The influence of different bearing types to the friction torque without thrust force at $90^{\circ} \mathrm{C}$

Figure 9 shows the trend of the friction torque at three different bearings types. As might be expected, the friction torque increases with the speed. The curves of the full- floating and semi-floating plain bearing show speed increases an approximately linear course of the friction torque. The highest friction torque in this bearing comparison is caused by the bearing tin of the hydrodynamic radial bearing. The examined ball bearing has the lowest friction torque trend. This is caused by the ball elements; the rolling friction type is less than plain friction type. At higher speeds, the advantage of the ball bearing against the plain bearing variants is lower.
The slightly increased friction or slightly increased friction losses of semi-floating or full-floating plain bearing is mainly because of the higher shear stresses caused by the higher speed difference of the bearing tin to the rotating shaft within the oil, which in turn leads to higher friction torques. Figure 10 illustrates the trend of the oil volumetric flow of the three investigated bearing types depend of the speed.

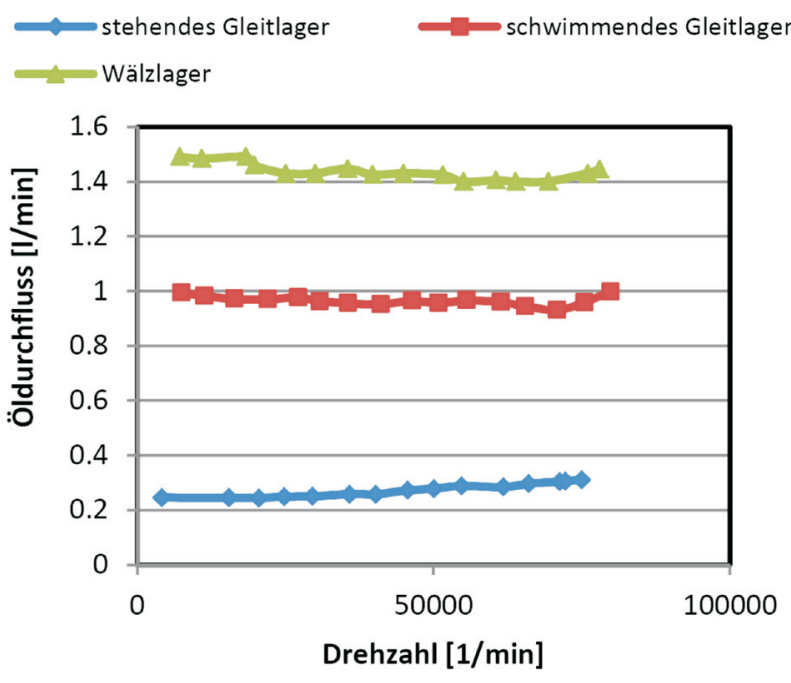

Fig. 10. The oil volumetric flow with influence of bearing types without thrust load at $90{ }^{\circ} \mathrm{C}$

The oil flow has a nearly constant characteristic versus the speed at each examined bearing variant. The highest oil throughput caused by the ball bearings. This is approximately $1.4 \mathrm{l} / \mathrm{min}$. This high oil flow is structurally designed to cool the rotor shaft and the bearing components can sufficiently. A large difference in the flow of oil between the bearings is striking. The also high oil flow of the floating plain bearing serves primarily to building the damping film between the bearing tin and housing. Figure 11 illustrates the trend of the friction power of the various radial bearing over the speed.

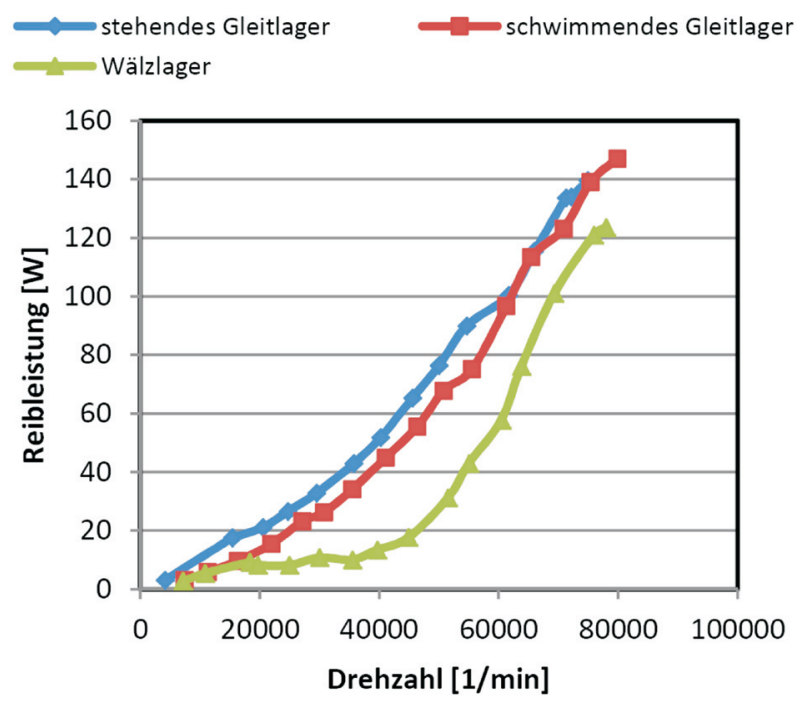

Fig. 11. The influence of bearing without friction power under axial force at $90{ }^{\circ} \mathrm{C}$ 
The friction of ball bearings is considerably lower than for the plain bearing variants at low engine speeds, this leads to a significantly improved dynamic response during acceleration and an exhaust gas turbocharger. At speeds over $60,000 \mathrm{rpm}$, the friction performance of the different variants are lower.

\subsection{Variation of the thrust force}

In this variation, the three bearing types of the turbocharger shaft are varied from the previous section thrust force and measured in a speed range from $5000 \mathrm{rpm}$ to $80,000 \mathrm{rpm}$ by a thrust load of $20 \mathrm{~N}$ and $40 \mathrm{~N}$. The oil pressure is kept constant at 3 bar absolute and the oil temperature adjusted to $90^{\circ} \mathrm{C}$. To determine the frictional losses torque and speed are determined by measurement.

\subsubsection{Influence of thrust load on a full-floating plain bearing}

Figure 12 illustrates the trend of the friction torque for various thrust forces in full-floating plain bearing depending on speed.

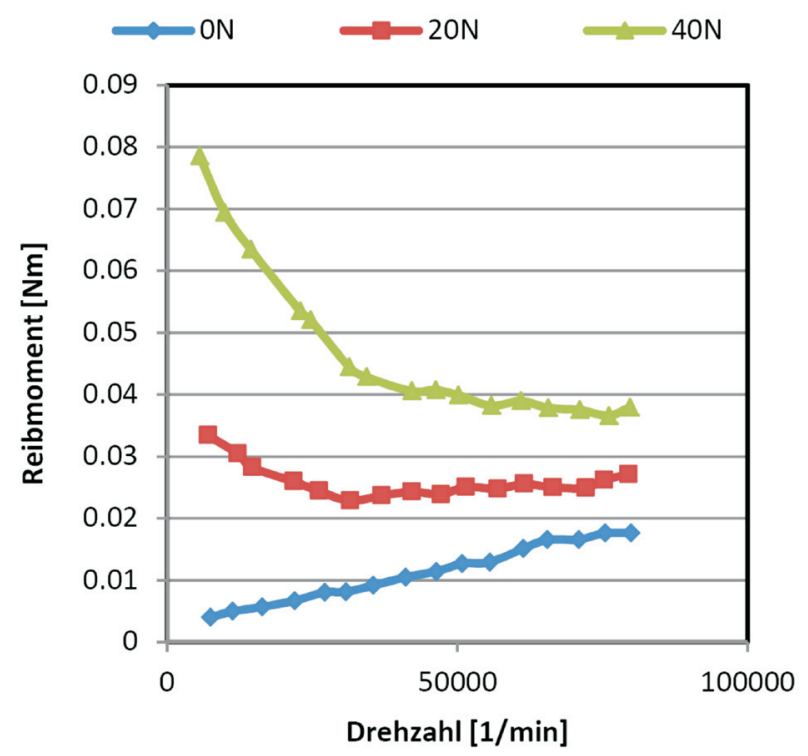

Fig. 12. The friction torque under the influence of the axial force, floating plain bearings at $90^{\circ} \mathrm{C}$

Figure 12 illustrates the trend of the friction torque at various thrust forces in a full-floating plain bearing depending on speed. The frictional torque increases with higher thrust forces. Especially in the low speed range a large difference in frictional torque between the various thrust forces can be seen.

The hydrodynamic thrust bearing is constructed that it enables the rotational movement between the disc and the distance tin. Through a supply channel, oil can flow into the oil chambers of the fixed thrust bearing. From these chambers, the oil between thrust bearing and the disc is flowing, between thrust bearing and distance disc. The next figure shows the basic structure of the thrust bearing.

If a one-sided thrust load is applied, the components can be brought in a rotary motion with a higher force, since they are pressed together. In addition, the oil which is between the disc and the thrust bearing can be abruptly displaced. This leads to an adhesive ( $\mathrm{n}=0 \mathrm{rpm})$ or a mixed friction $(\mathrm{n}>0 \mathrm{rpm})$. The effect is higher at low speeds and at higher thrust load. Nearly fixed components of the axial and radial bearing (by $\mathrm{n}=0 \mathrm{rpm}$ ) increases the relative speed difference between the radial bearing tin and the shaft, which reaches a speed of up to 80,000 rpm. Therefore the shear stress decreases within the oil film significantly and a high frictional torque is produced. This can be seen in Fig. 12, because the friction torque of the load by $40 \mathrm{~N}$ in the speed range from 5000 to $40,000 \mathrm{rpm}$ is much higher than the friction torque of the load at $20 \mathrm{~N}$.

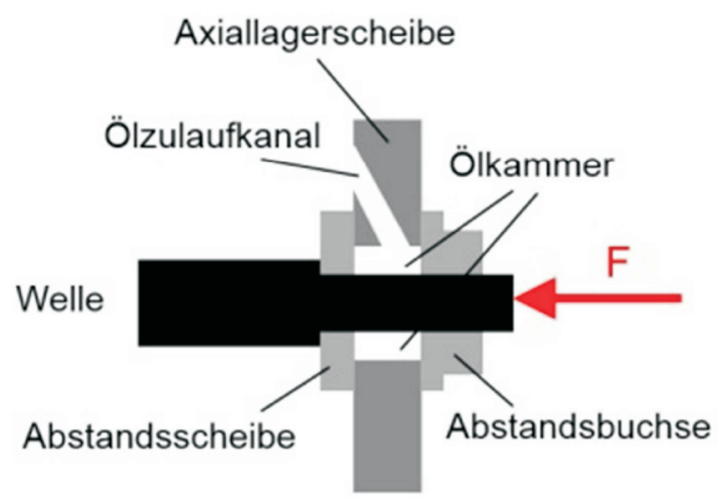

Fig. 13. The structure scheme of a hydrodynamic thrust bearing

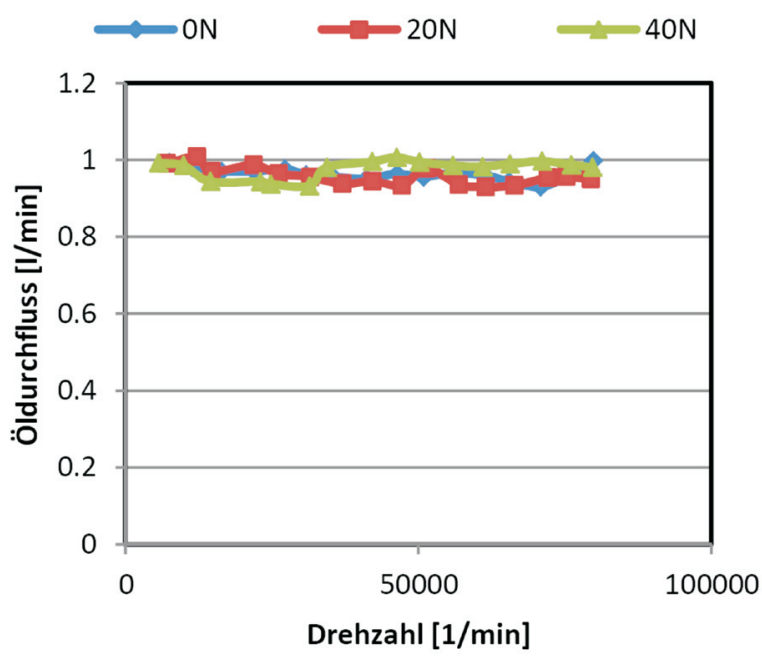

Fig. 14. The oil volumetric flow by influence of thrust force, in fullfloating plain bearings at $90{ }^{\circ} \mathrm{C}$

Only with increasing speeds a sufficiently large lubricating film could be reached between the surfaces to the compressed again to separate the components from each other and cause a sliding fluid contact. The oil film, which is separating the components, can re-rotate the bearing components take place, whereby the speed difference becomes smaller. By lower shear forces, the friction torque is reduced. From a speed by 40,000 rpm of separating oil film also ensures a constant trend of the friction torque.

Figure 14 illustrates the trend of the oil flow by different thrust forces in a full-floating plain bearing depending 
of speed. The thrust load doesn't have an influence of the oil flow.

Figure 15 shows the results of friction power with different thrust load depending of speed.

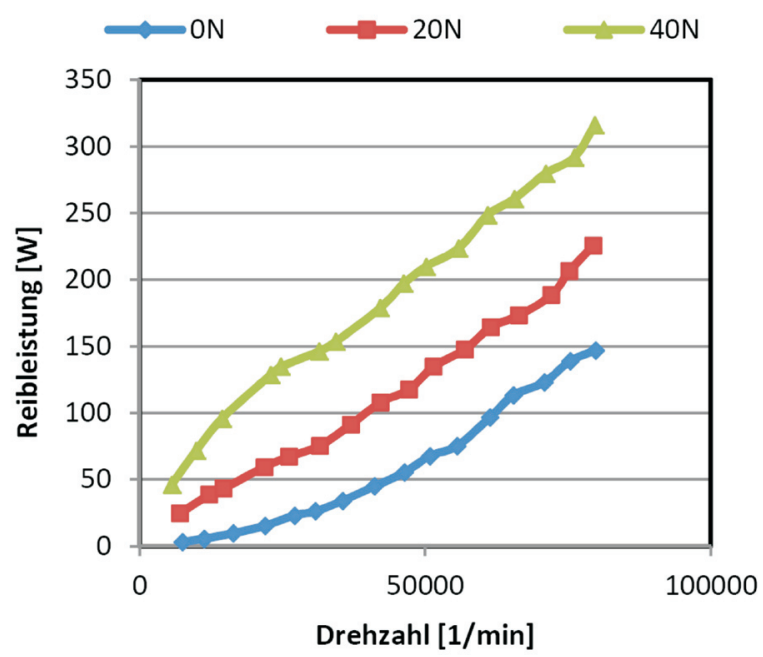

Fig. 15. The friction losses with influence of thrust load, in full-floating plain bearings at $90^{\circ} \mathrm{C}$

The friction losses increase with each loaded thrust force proportional to the speed. An increased thrust force causes higher friction losses. Here, the distance between the frictions is less than the performance data between $20 \mathrm{~N}$ and $40 \mathrm{~N}$ as well as between $0 \mathrm{~N}$ and $20 \mathrm{~N}$. An explanation on this matter provides the construction of the hydrodynamic thrust bearing, which is described in Fig. 13.

\subsubsection{Influence of thrust force on a semi-floating plain bearing}

In the further experiment, the thrust force is increased in two steps in the semi-floating plain bearing.

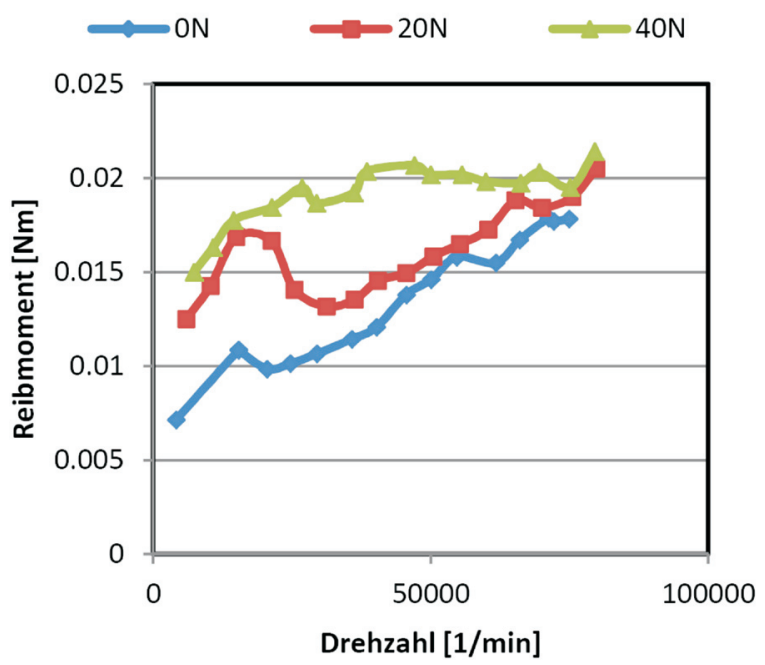

Fig. 16. The friction torque with influence of the thrust load in a semi-floating plain bearing at $90{ }^{\circ} \mathrm{C}$

The friction torque increases slightly with higher thrust forces. The frictional torques with thrust load is only slightly above the frictional torque without thrust load. In the speed range between $10,000 \mathrm{rpm}$ and $60,000 \mathrm{rpm}$ by a load of $40 \mathrm{~N}$ and in the speed range between 5000 to $30,000 \mathrm{rpm}$ by $20 \mathrm{~N}$, the influence of thrust load is higher than at higher speeds, where a convergence of all curves takes place during thrust force.

Analog the explanation in chapter 3.5.1 the components of the thrust bearing are pressed together, by the thrust force of $20 \mathrm{~N}$ or $40 \mathrm{~N}$. In a semi-floating plain bearing tin, the resulting impact is comparatively small, since even in the absence of a thrust force, the fixing of the tin has a high difference in speed between the shaft and the bearing tin. Only a small increase in friction torque is caused by the application of a thrust force. Figure 17 illustrates the trend of the oil flow by different thrust loaded in semi-floating plain bearing depending on speed.

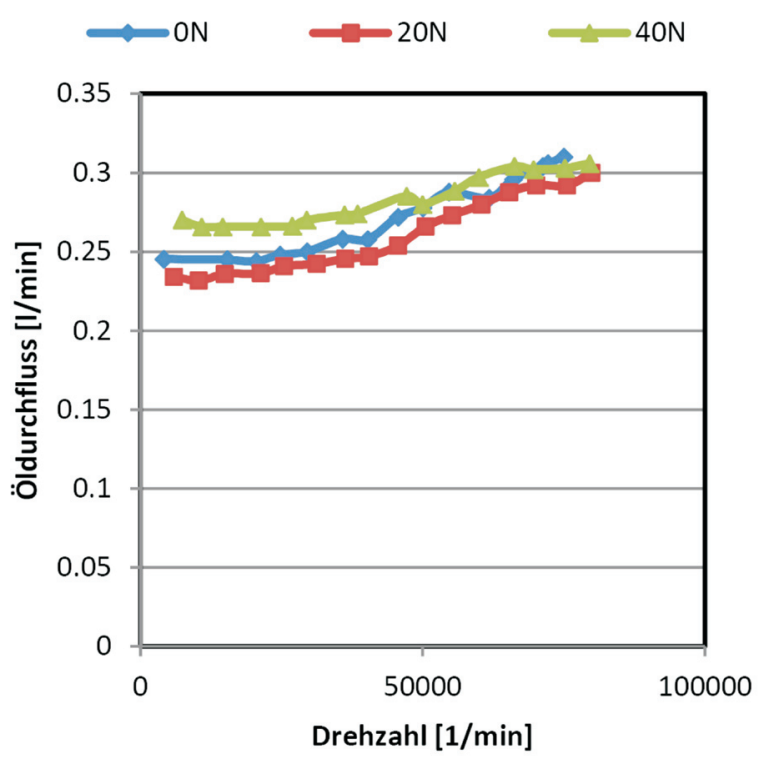

Fig. 17. The oil volumetric flow with influence of thrust force, in semi-floating plain bearing at $90{ }^{\circ} \mathrm{C}$

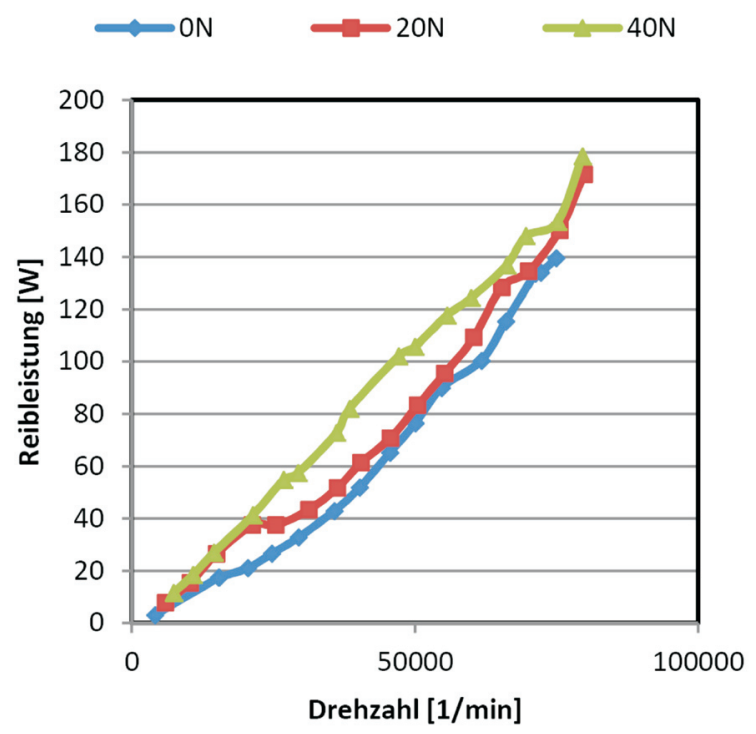

Fig. 18. Friction losses with influence of thrust load, in semi-floating plain bearings at $90^{\circ} \mathrm{C}$ 
The oil flow increases slightly by a load in the axial direction. It is thought that by displacing the thrust bearing the ratio of the inflow cross sections between plain bearing and bypass channel is changed and can flow more oil through the bypass channel.

Figure 18 represents the trend of the friction losses at various thrust forces in a semi-floating plain bearing depending on speed.

The curves of the friction losses with thrust load of $0 \mathrm{~N}$, $20 \mathrm{~N}$ and $40 \mathrm{~N}$ have a small parallel shift in the curves on almost the same curve.

\subsubsection{Influence of thrust force on a ball bearing}

Figure 19 illustrates the trend of the frictional torque in a ball bearing by different thrust loaded depending on speed.

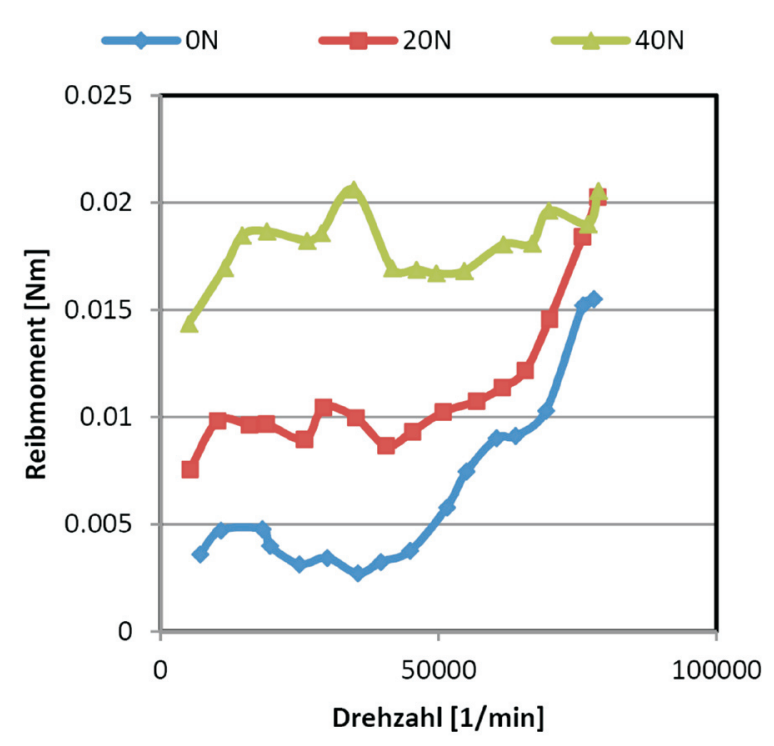

Fig. 19. The friction torque with influence of thrust load, in a ball bearing at $90{ }^{\circ} \mathrm{C}$

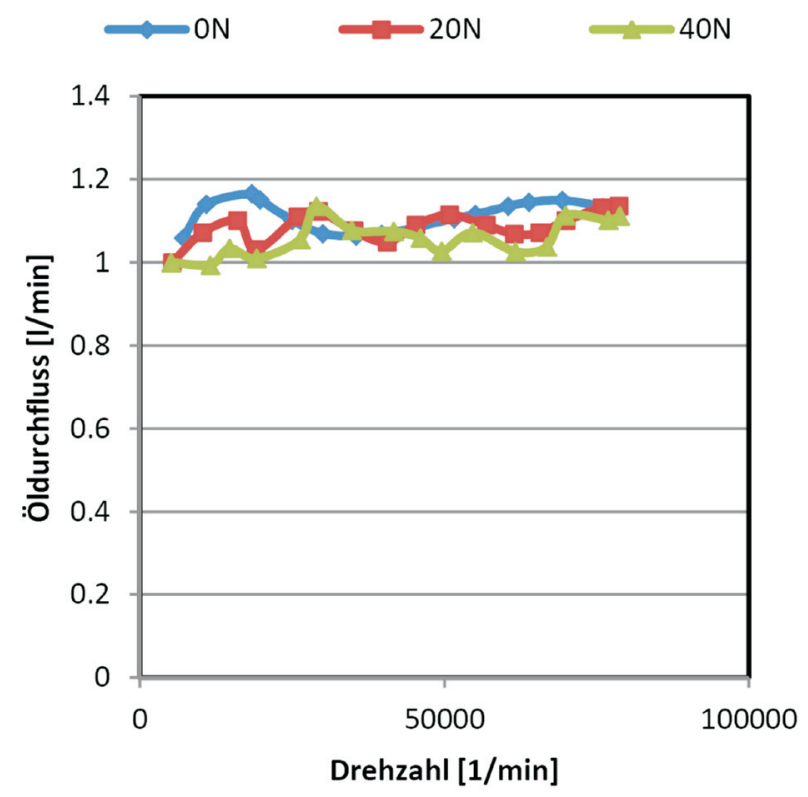

Fig. 20. The oil flow with the influence of thrust load, in ball bearing at $90{ }^{\circ} \mathrm{C}$
The friction torque increases at higher thrust load. In contrast to the reaction of a plain bearing by a thrust load, in the ball bearing there is nearly no influence of the friction torque with increased thrust load, which was caused without this load. The design of the ball bearing, which is a diagonally ball bearing allows to absorb the radial load and the thrust load. Therefore, the friction increases are almost proportional to the thrust force. Figure 20 shows the oil flow of a ball bearing by changing the thrust load.

There is a clear increase, that the thrust load has no influence on the oil flow. A thrust load shifts the balls in the ball bearing insignificant, whereby the cross-section for the flow barely changes. Figure 21 illustrates the trend of the friction losses at various the thrust load of a ball bearing depending on speed.

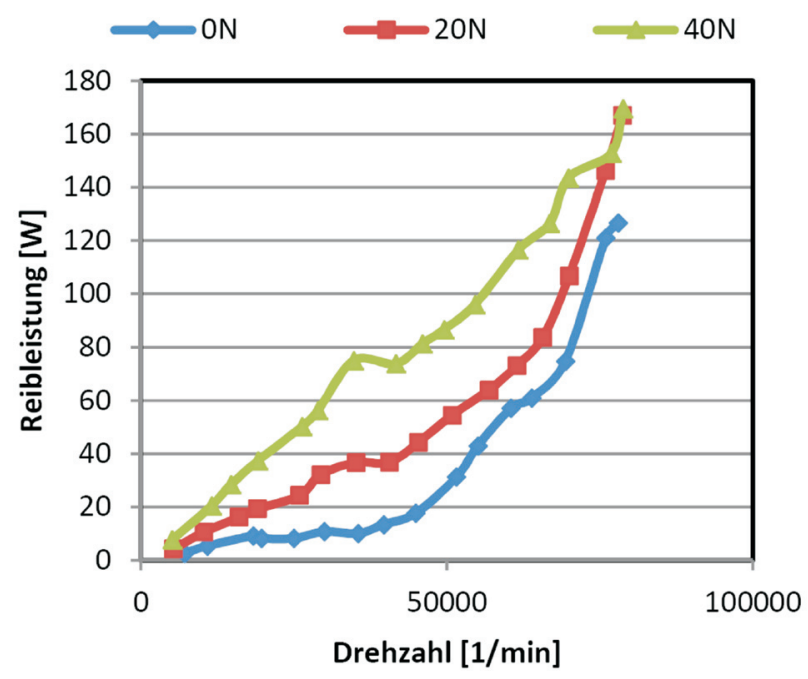

Fig. 21. The friction losses with influence of thrust load, in ball bearings at $90{ }^{\circ} \mathrm{C}$

The friction losses increases with each applied thrust load proportional to the speed. The highest frictional power is thereby caused by a thrust load of 40 N. Similar to a fullfloating and semi-floating plain bearing the friction of ball bearings is the lowest with influence of thrust load.

\subsection{Influence of the load direction in a thrust bearing}

In the following investigation, the axial bearing is charged with $+20 \mathrm{~N}$ and $-20 \mathrm{~N}$ and examined in a speed range from $10,000 \mathrm{rpm}$ to $80,000 \mathrm{rpm}$. The oil pressure is thereby maintained constant at 3 bar and adjusted the oil temperature at $90{ }^{\circ} \mathrm{C}$. The friction torque and speed are determined during this measurement. This test allows evaluating, whether the direction of the thrust force has an effect on the friction losses.

Figure 22 illustrates the trend of the friction torque by various the thrust forces when pulling or pushing the shaft. The curves of the friction torque show already discussed in chapter 3.5.1 the influence of thrust load. The need of oil film between the bearings surfaces of the thrust bearing occurs at increased starting torques at low speeds. With increasing speed, a sufficiently large lubricating film reaches these bearings and a fluid sliding film is built. The friction 


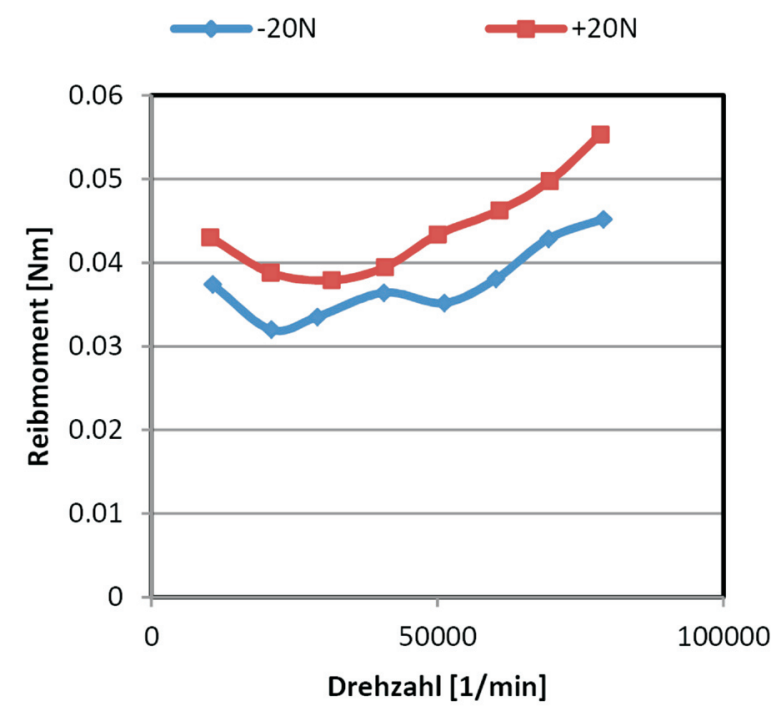

Fig. 22. The friction torque with the influence of the load direction in a thrust bearing at $90{ }^{\circ} \mathrm{C}$

\section{Friction performance benchmark}

As part of investigations on the Ostfalia friction test rig over 50 turbochargers were measured.

The extensive results allow putting up a map of friction power losses depending on speed. All turbochargers were measured at 3 bar oil pressure and $90{ }^{\circ} \mathrm{C}$ oil temperature without thrust load. Figure 24 shows the result of the benchmark friction losses map.

In the map in Fig. 24 there is a distinction between plain bearing (red and blue) and ball bearings (black). It is immediately apparent that there are in fact turbochargers with hydrodynamic radial bearing, which have lower friction losses than TC with ball bearings. This is due to special tribological measures in structure of bearing systems.

Furthermore, it was once again distinguished in the field of hydrodynamic radial bearings between applications for gasoline (in blue) and diesel engines (in red). It should be noted that there are bearings with a lower friction losses than turbocharger with ball bearings.

torque, which is caused by a forward (pushing) force differs from the torque of pulling force. The results clearly show that the thrust bearing caused by its asymmetrical bearing structure has a different friction torque depending on pulling or pushing shaft.

Figure 23 illustrates the trend of the friction losses at various thrust forces that are applied in pulling and pushing direction depending on speed. In a speed range from $10,000 \mathrm{rpm}$ to $40,000 \mathrm{rpm}$ the curves are nearly the same. From a rotation speed more than 40,000 rpm the friction increases more under the push load of $+20 \mathrm{~N}$ compared to the pulling load by $-20 \mathrm{~N}$.

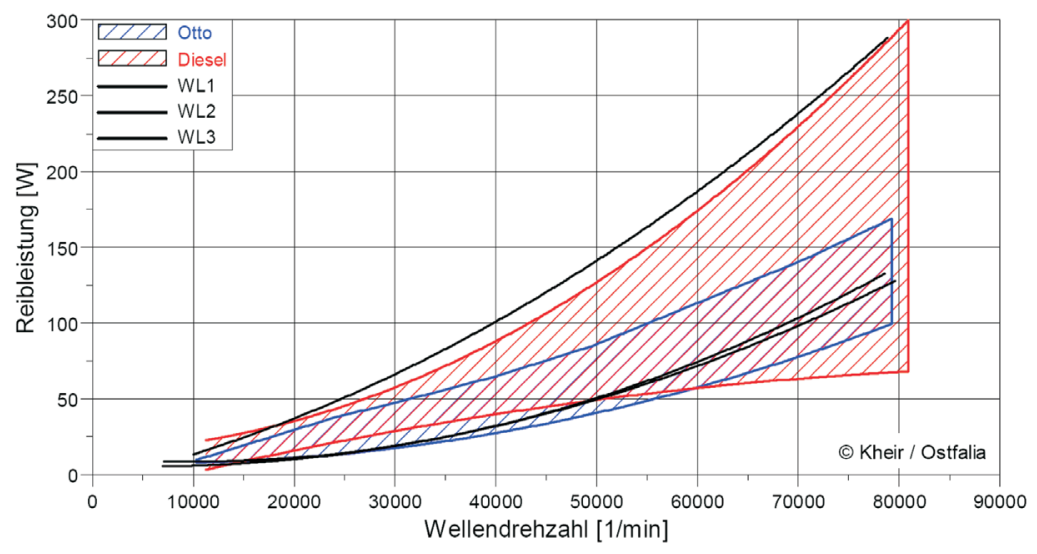

Fig. 24. The comparison of different bearing systems of turbochargers

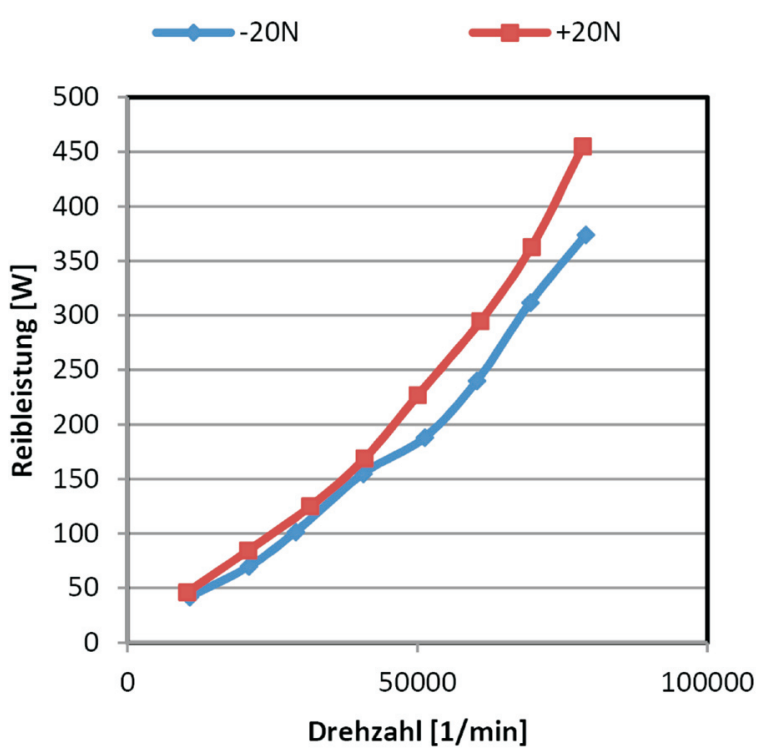

Fig. 23. The friction power influenced the direction of action of the axial force at $90{ }^{\circ} \mathrm{C}$
The boost pressure of a diesel engine is much higher than that of a gasoline engine.

This results in higher thrust forces on the bearing; it must be absorbed by a larger thrust bearing. Although the measurements with unloaded thrust bearing was applied, the larger thrust bearing in diesel turbocharger cause a higher friction losses than turbocharger by gasoline engines.

The next Fig. 25 shows analogue to Fig. 24 the friction losses depending on the shaft diameter speed. So the constructional geometries of the shaft is includes the speed, so the maps shows the specific friction losses of more than 50 turbocharger were measured.

\section{Summary}

This article discusses the modern turbocharger bearings systems and its analysis. A specially developed and designed friction power test rig is introduced in this article. The friction of radial- and thrust bearings was discussed in detail. The resulting conclusions are briefly summarized here.

The oil temperature is a critical factor to minimize the friction losses, the friction losses decreases by increasing oil 


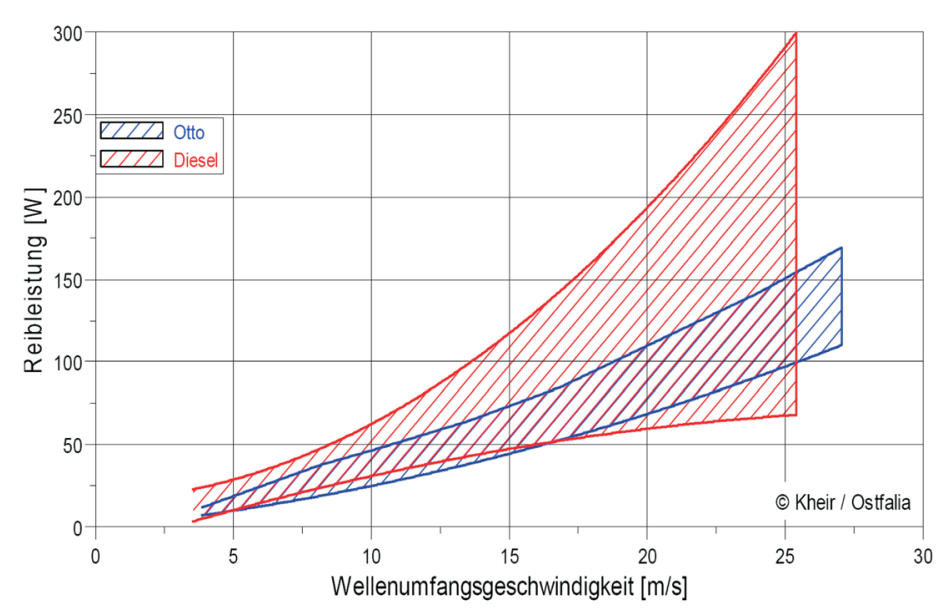

Fig. 25. The comparison of different application in plain bearings depend on shaft diameter speed

temperature. Here, the friction torque shows a clear downward trend with higher oil temperatures. This is especially noticeable at low speeds. The oil flow increases with an increase of the oil temperature. This results by increased splash losses and increased heat dissipation.

With respect to the oil pressure, an influence is recognizable only at higher speeds. The friction torque decreases at high speeds by a pressure reduction. The result is a lower friction performance compared to higher oil pressure values. The oil flow ratio is above the speed curve usually constant and increases with the increase of the oil pressure.

An axial force applied on a full-floating plain bearing causes a considerable increase in the friction torque. This is particularly evident at low engine speeds. With an increase of the rotation speed, the friction torque decreases. In semifloating plain bearing the influence of the thrust force is smaller. In a fixed bearing tin there is a higher difference in speed between the tin and the shaft so it occurs when it is loaded by a thrust force; the difference in torque is lower than for a full-floating bearing tin. Consequently, the trends of the friction torque with thrust load have the same shape as the curve of the friction torque in the unloaded thrust bearing condition. In regard to the oil flow with an influence to a thrust load there isn't any affect by any bearing.

When comparing three different bearing types at $90{ }^{\circ} \mathrm{C}$ oil temperature and 3 bar oil pressure without thrust load, the trends of the friction torque for semi-floating and fullfloating plain bearing shows nearly identical curves. The friction torque of the plain bearing is also higher than the friction torque of the tested ball bearing. The friction losses by a semi-floating bearing are a little bit higher than the friction in a full-floating bearing. The reason for this hypothesis is the different in the speed difference between shaft and bearing tin. There is also a big discrepancy in the oil flow between the bearing types. The greatest flow generates the ball bearing requires theses high flow for heat dissipation of the bearing components. The full-floating plain bearing also shows a high flow rate of about one liter per minute. This oil flow is needed to build the hydrodynamic oil film and to wash around the bearing tin to minimize any vibrations.
More friction losses were determined by an influence of the load direction in a thrust bearing, probably caused by the asymmetrical structure of the bearing oil flow.

The friction power test rig constructed by Ostfalia, University of Applied Sciences can make an important contribution, to evaluate the simulation results of bearings systems to match them with measurement results and to analyze different bearings options under realistic conditions.

\section{Acknowledgement}

The authors would like to thank the research and development department of Volkswagen AG for the support.

\section{Bibliography}

[1] Baar R., Porzig D., Rätz H.: Systemspezifische Schmierfilmdissipation in den radialen und axialen Lagerstellen von Abgasturboladern unter realen Betriebsbedingungen mit unterschiedlichen Ölzuführungsrandbedingungen Abschlussbericht über das Vorhaben Nr. 1020 (AIF-Nr. 16230).

[2] Smiljanovski V., Schorn N., Scharf J., Funken B., Pischinger S.: Messung des Turbinenwirkungsgrades bei niedrigen Turboladerdrehzahlen. 13. Aufladetechnische Konferenz Dresden, 2008.

[3] Schmitt S., Schmid W., Hertweck G., Schlegl M., Staudacher S.: High-Precision measurements of friction measurements of friction losses in turbochargers. 12. Aufladetechnische Konferenz Dresden, 2007.

Prof. Robin Vanhaelst, DSc., DEng. - Professor in the Faculty of Automotive Engineering Ostfalia University of Applied Sciences, Germany.

e-mail:rvanhaelst@ostfalia.de

Alaa Kheir, MEng. - Faculty of Automotive Engineering Ostfalia University of Applied Sciences, Germany.

e-mail:kheiralaa@googlemail.com
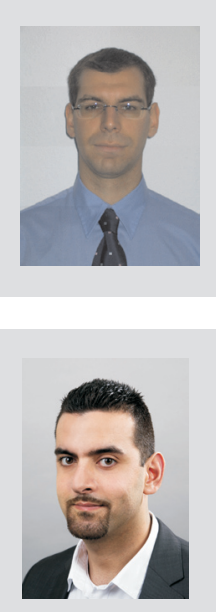

Jakub Czajka, DEng. - Volkswagen Poznań Sp. z o.o. Poznań, Poland. e-mail: jakub.czajka@vw-poznan.pl

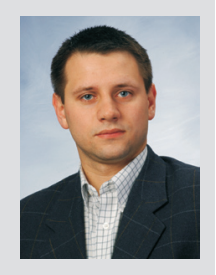

